\title{
Shear-wave elastography as a tool in the assessment of thyroid nodules
}

\author{
Carlos Paredes-Manjarrez, ${ }^{1}$ Demetrio Arreola-Cháidez, ${ }^{1 *}$ Andrés Magdalena-Buitrago, ${ }^{2}$ \\ Aldo Ferreira-Hermosillo, ${ }^{1}$ José F. Avelar-Garnica ${ }^{1}$ and Rocío Arreola-Rosales ${ }^{1}$ \\ ${ }^{1}$ Specialty Hospital, Centro Médico Nacional Siglo XXI, Instituto Mexicano del Seguro Social, Mexico City, Mexico; ${ }^{2}$ Diagnóstico e Imágenes del \\ Valle, Instituto Prestador de Salud, Cali, Colombia
}

\begin{abstract}
Introduction: Shear-wave elastography (SWE) has been shown to be predictive of malignancy in thyroid nodules. Objective: To determine, by SWE, the stiffness cutoff point with the highest specificity and sensitivity to detect thyroid nodules that require surgery. Methods: Cross-sectional study of ultrasonographically-evaluated patients for thyroid nodules over a period of three years; the TI-RADS classification system was used, and nodule stiffness was determined by SWE. Histopathological specimens were classified using the Bethesda system, and the stiffness cutoff point with the highest specificity and sensitivity was obtained using ROC curves. Results: Forty-one percent of the nodules were classified as TI-RADS 5, and 59 $\%$, as TI-RADS 1-4. In TI-RADS 5 nodules, median stiffness of those in Bethesda system IV-VI categories was $35.9 \mathrm{kPa}$; in nodules with TI-RADS 1-4, $21.6 \mathrm{kPa}$. In TI-RADS 5 nodules, a cutoff point $>32.5 \mathrm{kPa}$ had a specificity of $75 \%$ and sensitivity of $57 \%$ to detect those requiring surgery; in TI-RADS 1 to 4 nodules, a cutoff point of $21.5 \mathrm{kPa}$ had a specificity of $63 \%$ and sensitivity of $51 \%$. Conclusion: SWE-determined stiffness is useful to detect nodules that require surgical evaluation.
\end{abstract}

KEY WORDS: Thyroid cancer. Ultrasonography. Thyroid nodule.

\section{Elastografía por ondas de corte como herramienta en la evaluación de los nódulos tiroideos}

\section{Resumen}

Introducción: La elastografía por ondas de corte (SWE) ha demostrado ser predictiva de malignidad en nódulos tiroideos. Objetivo: Determinar mediante SWE, el punto de corte de la rigidez con mayor especificidad y sensibilidad para detectar nódulos tiroideos que requieren cirugía. Métodos: Estudio transversal de pacientes con nódulos tiroideos evaluados ultrasonográficamente en un periodo de tres años; se empleó la clasificación TI-RADS y mediante SWE se determinó la rigidez de los nódulos. Con el sistema Bethesda se clasificaron las muestras histopatológicas y mediante curva ROC se obtuvo el punto de corte de la rigidez con mayor especificidad y sensibilidad. Resultados: $41 \%$ de los nódulos fue TI-RADS 5 y $59 \%$, TI-RADS 1-4. En los TI-RADS 5, la mediana de rigidez de los nódulos con categoría IV-VI del sistema Bethesda fue de $35.9 \mathrm{kPa}$ y en los nódulos con TI-RADS 1-4, $21.6 \mathrm{kPa}$. En los nódulos TI-RADS 5, la rigidez > $32.5 \mathrm{kPa}$ tuvo especificidad de $75 \%$ y sensibilidad de $57 \%$ para detectar los que requieren cirugía; en los TI-RADS 1-4, el valor de corte de $21.5 \mathrm{kPa}$ tuvo especificidad de $63 \%$ y sensibilidad de $51 \%$. Conclusión: La rigidez determinada por SWE es útil para detectar nódulos que requerirán exploración quirúrgica.

PALABRAS CLAVE: Cáncer de tiroides. Ultrasonografía. Nódulo tiroideo. 


\section{Introduction}

Thyroid nodules are the most common endocrine tumors; $95 \%$ are benign in nature and $5 \%$ are neoplasms, mainly papillary thyroid cancer. ${ }^{1}$ According to the World Health Organization, the prevalence of thyroid cancer in the world is $1,977,846$ cases, with an incidence of 567,233 cases. In Mexico, it represents the second most prevalent cancer, with a total of 40,770 cases in $2018 .^{2}$

For risk of malignancy staging, thyroid nodules are classified according to the Thyroid Imaging Reporting and Data System (TI-RADS) scale according to their ultrasonographic characteristics. ${ }^{3}$ In 2017, Ha et al. analyzed the TI-RADS criteria published by the American College of Radiology (ACR), the American Thyroid Association (ATA) and the Korean Thyroid Association/Korean Society of Thyroid Radiology (KTA/KSThR); they demonstrated that the ACR criteria had the highest specificity (75\%) for malignancy detection, with the lowest rates of unnecessary biopsies (21\%). ${ }^{4}$ In April 2017, the ACR carried out an update that was called ACR-TI-RADS. ${ }^{5}$

Fine needle aspiration biopsy (FNAB) is the gold standard for determining whether thyroid nodules are benign or malignant. The result is classified with the Bethesda system, which establishes six categories based on the percentage of risk for malignancy: ${ }^{6}$

- I, unsatisfactory.

- II, benign (0 to $3 \%$ ).

- III, atypia of undetermined significance (5 to $15 \%$ ).

- IV, follicular neoplasm (15 to $30 \%$ ).

- V, suspicious for malignancy (60 to $75 \%$ ).

- VI, malignant (97 to $99 \%$ ).

However, FNAB is an invasive method that can cause local complications or have false negative results in up to $15 \%$ and that requires repetition of the procedure if the sample is insufficient. 7,8

Elastography-guided biopsy has helped to increase the capacity to differentiate between benign and malignant thyroid nodules. Ultrasound elastography is an imaging method that measures tissue elasticity and stiffness, ${ }^{9}$ and that in the last 20 years has been proposed for differentiating malignant neoplasms in different tissues, ${ }^{10}$ with the advantage of being inexpensive and non-invasive.

Quantitative elastography is a recent technique, available in advanced ultrasound systems. It involves obtaining images with the measurement of ultrasonic signals propagation in the tissues before and after compressive force application: when compressed, diseased tissues exhibit less deformation than healthy tissues. ${ }^{11}$ Both real-time and shear wave elastography (SWE) have been shown to be predictive of malignancy in thyroid nodules. ${ }^{12}$ In Mexico, their definitive role is still under evaluation.

\section{Methods}

A retro-prolective cohort study was carried out in a three-year period (January 2017 to July 2019) in patients of either gender, older than 18 years, who attended the Ultrasound Department of the Specialty Hospital at National Medical Center Siglo XXI, Mexican Institute of Social Security, referred for thyroid nodules FNAB. Patients with a previous diagnosis of thyroid cancer, with incomplete imaging examination or with an inadequate FNAB sample for pathological diagnosis (Bethesda I) were excluded, if the procedure could not be repeated.

\section{Ultrasound examination}

Ultrasound evaluation of the thyroid gland was performed in all patients with B-mode gray scale ultrasound and color Doppler ultrasound to assess composition, echogenicity, shape, margins and associated calcifications. With these characteristics, nodules were classified according to the TI-RADS system: ${ }^{5}$

- Benign, zero points.

- Not suspicious, two points.

- Slightly suspicious, three points.

- Moderately suspicious, four to six points.

- Highly suspicious, seven or more points.

To evaluate the usefulness of SWE, the nodules classified as TI-RADS 5 were compared to those classified as TI-RADS 1-4. Elastography was performed with an Aixplorer ${ }^{\circledR}$ equipment (Supersonic Imagine, Aix-en-Provence, France), with a linear transducer that uses a frequency of $18 \mathrm{MHz}$. Elastography values were evaluated with the Virtual Touch ${ }^{\mathrm{TM}} \mathrm{IQ}$ program (Siemens, Malvern, PA, USA), which uses five regions of interest (five samples of nodular stiffness) of 2 to 5 $\mathrm{mm}$ in diameter and reports mean kilopascals $(\mathrm{kPa})$ measured.

\section{Thyroid FNAB}

After asepsis and antisepsis, $1 \mathrm{~mL}$ of $2 \%$ lidocaine was infiltrated into the soft tissues. Percutaneous 
puncture was performed using ultrasound guidance until the nodule was reached and biological material was obtained by aspiration with a $20-\mathrm{G}$ needle; said material was placed on slides to perform smears and was fixed in absolute alcohol; the samples were evaluated by hospital pathologists who reported the cytology result using the Bethesda system. ${ }^{6}$ In our unit, thyroid nodules stratified as II and III according to the Bethesda classification require only surveillance, while those classified as IV, V and VI require surgical approach: IV and $\mathrm{V}$ require hemithyroidectomy, and $\mathrm{VI}$, total thyroidectomy.

\section{Statistical analysis}

Data were analyzed with the SPSS program, version 23. Normality of variables was assessed with the Kolmogorov-Smirnov test. Since these are non-parametric variables, quantitative results were expressed with medians and interquartile ranges. ANOVA was used to assess between-group differences according to TI-RADS classification. Mann-Whitney's U-test was used to evaluate the differences between TI-RADS 1-4 and TI-RADS 5 nodules. Qualitative variables were expressed as percentages and the differences between groups were evaluated with the chi-square test (in the case of two groups) and with McNemar's test in the case of three or more groups. To determine the SWE cutoff points for the detection of nodules that require surgical approach (classified as Bethesda system IV, $\mathrm{V}$ or $\mathrm{VI})$, receiver operating characteristics (ROC) curves were used. Cutoff points were selected with the Youden index (sensitivity + specificity -1$){ }^{13}$

\section{Ethical aspects}

The protocol was approved by the Local Research and Health Research Ethics Committee. Patients signed the informed consent letter for the performance of the procedures and for analysis of their information, after having being explained the purposes of the study. The procedures observed the ethical standards established in the Declaration of Helsinki.

\section{Results}

Out of 756 patients assessed for a thyroid nodule, $41 \%(n=309)$ were classified by ultrasound as ACR TI-RADS 5, and $59 \%(n=449)$, as TI-RADS 1-4; 90 $\%$ of total population were females, and median age was 57 years (46-66 years). Table 1 shows the demographic and ultrasound characteristics of the population according to TI-RADS classification.

As for ultrasound variables according to the TIRADS classification, no significant differences were observed in nodules largest diameter; in fact, TIRADS 5 thyroid nodules are smaller (median, $1.41 \mathrm{~cm}$ ) in comparison with those classified as TI-RADS 1 (median, $2.05 \mathrm{~cm}$ ). A difference was observed between the margins of the nodules depending on the TI-RADS classification, since the lower this classification was (1 and 2), the smoother the observed edges, in contrast to TI-RADS grade 4 and 5 nodules, which had lobed margins and, some of them, extrathyroid extension. Another different variable between groups was the composition: a predominantly cystic component was observed in all TI-RADS 1 nodules (100\%) and only in $1 \%$ of TI-RADS 5 nodules, while a predominantly solid component was found in $79 \%$ of TI-RADS 5 nodules and in none of TI-RADS 1 and 2 nodules.

The cytopathology result of the nodules regarded as TI-RADS 1 and 2 was mostly benign (Bethesda categories II and III), while the percentage of Bethesda IV to VI reports did increase in TI-RADS stages 3 to $5(p<0.001)$. Bethesda I (insufficient sample) was recorded in $21 \%$ of biopsied nodules, which was not statistically different between groups, regardless of their TI-RADS classification (Table 1). Patients with Bethesda I nodules were censored from further statistical analyses. When the nodules were grouped by TI-RADS 5 and TI-RADS 1-4, as well as by Bethesda I, II-III and IV-VI, those classified as TIRADS 5 were distributed as follows: $20 \%$ were classified as Bethesda I, $38 \%$ as Bethesda II-III and $42 \%$ as Bethesda IV-VI. As for TIRADS 1-4 nodules, the distribution was as follows: $22 \%$ were classified as Bethesda I, $64 \%$ as Bethesda II-III and $14 \%$ as Bethesda IV-VI.

When the TI-RADS 5 and the TI-RADS 1-4 groups and the elastography values with the Bethesda system classification were compared, nodule stiffness was observed to increase depending on the cytopathological classification, so that TI-RADS 5 nodules with low Bethesda category (II-III) had a median of $21.1 \mathrm{kPa}(14.3$ to $33 \mathrm{kPa})$, while the median was $35.9 \mathrm{kPa}(22.6$ to $68.6 \mathrm{kPa})$ in those classified at a high Bethesda category (IV- VI), $p<0.001$. As for TIRADS 1-4 nodules, those with Bethesda I-II category had a median of $17.7 \mathrm{kPa}(12.1-27 \mathrm{kPa})$, while those stratified as Bethesda IV-VI had a median of $21.6 \mathrm{kPa}$ (13.7 to $38.5 \mathrm{kPa}$ ), $\mathrm{p}=0.009$. 
Table 1. Demographic and elastographic characteristics of the population

\begin{tabular}{|c|c|c|c|c|c|c|}
\hline Variables & $\begin{array}{l}\text { TI-RADS } 1 \\
(n=30)\end{array}$ & $\begin{array}{c}\text { TI-RADS } 2 \\
(n=58)\end{array}$ & $\begin{array}{c}\text { TI-RADS } 3 \\
(n=101)\end{array}$ & $\begin{array}{l}\text { TI-RADS } 4 \\
(n=260)\end{array}$ & $\begin{array}{l}\text { TI-RADS } 5 \\
(\mathrm{n}=309)\end{array}$ & $p$ \\
\hline Age, years ${ }^{\ddagger}$ & $64(55-68)$ & $52(44-65)$ & $53(42-65)$ & $59(46-68)$ & $57(45-64)$ & NS \\
\hline Gender ( $\%$ of females) & 90 & 97 & 94 & 84 & 87 & NS \\
\hline Lesion longest diameter $(\mathrm{cm})^{\ddagger}$ & $2.05(0.80-2.53)$ & $\begin{array}{c}1.89 \\
(1.13-2.92)\end{array}$ & $1.70(1.13-3.03)$ & $1.48(0.95-2.2)$ & $1.41(0.99-2.34)$ & NS \\
\hline $\begin{array}{l}\text { Composition } \\
\text { Cystic (\%) } \\
\text { Mixed (solid/cystic) (\%) } \\
\text { Solid (\%) }\end{array}$ & $\begin{array}{c}100 \\
0 \\
0\end{array}$ & $\begin{array}{c}29 \\
71 \\
0\end{array}$ & $\begin{array}{c}3 \\
22 \\
75\end{array}$ & $\begin{array}{c}3 \\
28 \\
69\end{array}$ & $\begin{array}{c}1 \\
20 \\
79\end{array}$ & $<0.001^{*}$ \\
\hline $\begin{array}{l}\text { Margins } \\
\text { Smooth or ill-defined (\%) } \\
\text { Lobulated and irregular (\%) } \\
\text { Extra-thyroid extension (\%) }\end{array}$ & $\begin{array}{c}100 \\
0 \\
0\end{array}$ & $\begin{array}{c}100 \\
0 \\
0\end{array}$ & $\begin{array}{c}99 \\
1 \\
0\end{array}$ & $\begin{array}{l}78 \\
16 \\
6\end{array}$ & $\begin{array}{l}35 \\
42 \\
23\end{array}$ & $<0.001^{*}$ \\
\hline Stiffness $(\mathrm{kPa})^{\ddagger}$ & $\begin{array}{c}11.86 \\
(9.41-22.40)\end{array}$ & $\begin{array}{c}15.96 \\
(9.76-21.84)\end{array}$ & $\begin{array}{c}18.48 \\
(12.87-27.81)\end{array}$ & $\begin{array}{c}18.80 \\
(13.03-30.94)\end{array}$ & $\begin{array}{c}25.52 \\
(16.53-42.60)\end{array}$ & $<0.001^{\star *}$ \\
\hline $\begin{array}{l}\text { Bethesda } \\
\text { I (\%) } \\
\text { II-III (\%) } \\
\text { IV-VI (\%) }\end{array}$ & $\begin{array}{l}20 \\
70 \\
10\end{array}$ & $\begin{array}{c}21 \\
74 \\
5\end{array}$ & $\begin{array}{l}20 \\
61 \\
19\end{array}$ & $\begin{array}{l}25 \\
51 \\
24\end{array}$ & $\begin{array}{l}20 \\
38 \\
42\end{array}$ & $\begin{aligned} & N S \\
< & 0.001^{*} \\
< & 0.001^{*}\end{aligned}$ \\
\hline
\end{tabular}

Using a ROC curve (Fig. 1), the cutoff point that was obtained for predicting TIRADS 5 nodules that require surgical approach was $32.5 \mathrm{kPa}$, with an area under the ROC curve (AUROC) of $0.69(95 \% \mathrm{Cl}=0.63$ 0.76 ), specificity of $75 \%$, sensitivity of $57 \%$, negative predictive value of $60 \%$ and positive predictive value of $72 \%$. Nodules with a value higher than this point had an odds ratio of $3.97(95 \% \mathrm{Cl}=2.7-6.8)$ for having a Bethesda IV-VI result.

The cutoff point for predicting TI-RADS 1-4 nodules that require surgical approach is $21.5 \mathrm{kPa}$, with an AUROC of $0.59(95 \% \mathrm{Cl}, 0.52-0.66)$, sensitivity of $51 \%$, specificity of $63 \%$, negative predictive value of $78 \%$ and positive predictive value of $31 \%$. Nodules with a value higher than this point had an odds ratio of $2.53(95 \% \mathrm{Cl}=1.43-4.48)$ for having a Bethesda IV-VI result (Fig. 2).

\section{Discussion}

In the evaluation of this work, the ACR TI-RADS scale for the classification of thyroid nodules was observed to have high specificity, but low sensitivity, which is useful in a screening test; however, in TIRADS 5 thyroid nodules, the sensitivity of the test is very low, which leads to the performance of numerous unnecessary FNABs. ${ }^{14}$ In this study, $48.6 \%$ of biopsies had a benign or inconclusive result $(20.1 \%$ were classified as Bethesda I, and $28.5 \%$, as Bethesda II).

Due to the above, using complementary ultrasound imaging modalities such as SWE is essential, which combined with the TI-RADS criteria showed a sensitivity of $84 \%$ for the characterization of thyroid nodules.

One of the main characteristics of gray scale ultrasound is that consistency of the nodule can be visualized; the more solid a nodule is, the more likely it is for it to be malignant. Seventy-nine percent of the nodules classified as TI-RADS 5 were observed to be solid or almost solid, which is consistent with the results of other investigations where the solid component was associated with a sensitivity of $95 \%$ and specificity of $48.7 \% .^{15}$

In our study, values higher than $32.5 \mathrm{kPa}$ were associated with a higher risk of a Bethesda IV-VI result and, therefore, with the need for surgery. We observe that SWE values increase as the Bethesda category increases; therefore, elastography can provide guidance on the degree of malignancy of the nodule and the place to obtain the biopsy sample, since it is possible for the site with the greatest stiffness and solid component to be identified. 


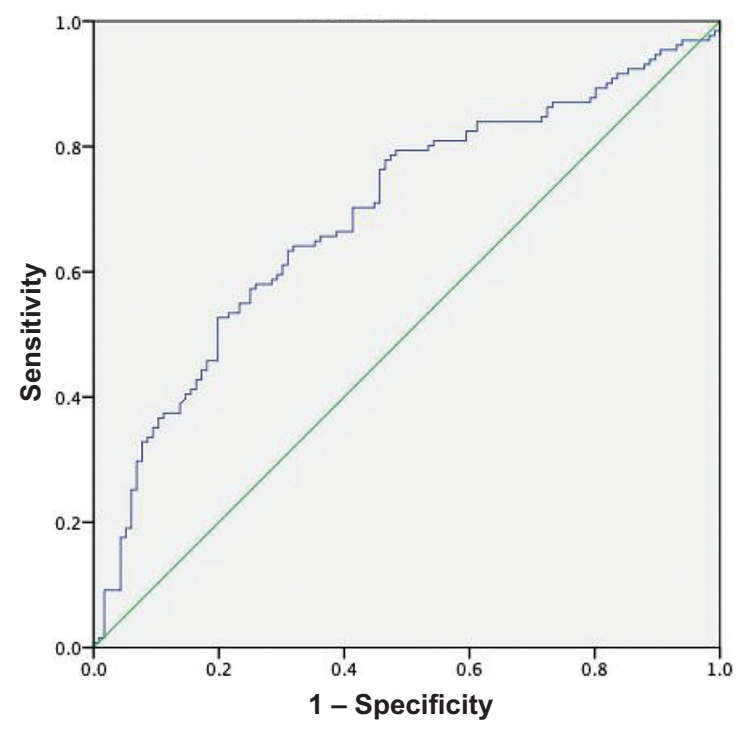

Figure 1. ROC curve of shear wave elastography values in TI-RADS 5 nodules. The cutoff point with the highest sensitivity and specificity for detecting nodules requiring surgery was $32.5 \mathrm{kPa}$.

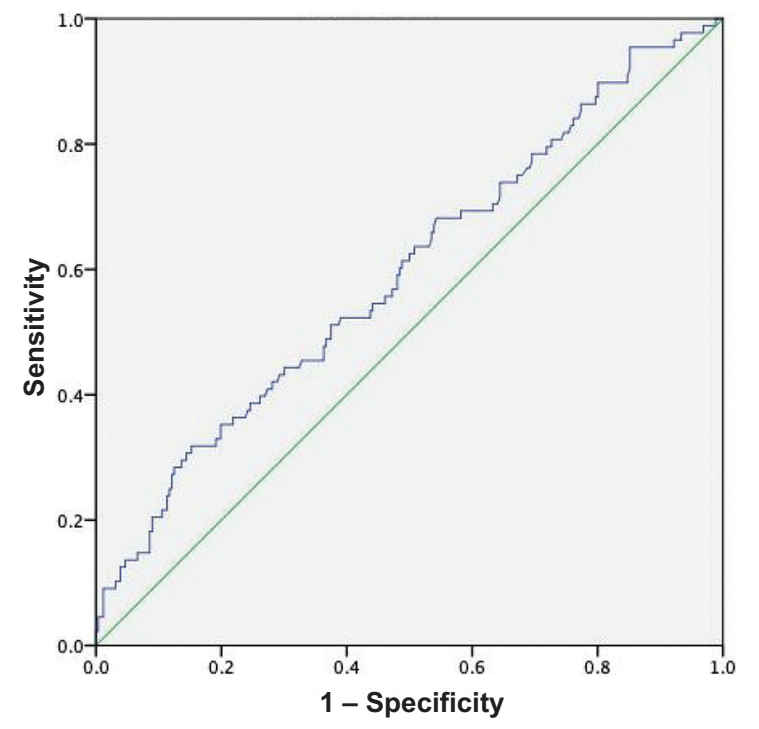

Figure 2. ROC curve of shear wave elastography values in TI-RADS 1-4 nodules. The cutoff point with the highest sensitivity and specificity for detecting nodules requiring surgery was $21.5 \mathrm{kPa}$.

Hang et al. observed that values lower than $22.5 \mathrm{kPa}$ predict benignity, which agrees with what we found in TI-RADS 1-4 nodules (median of $21.6 \mathrm{kPa}$ ) ${ }^{16}$ in that investigation, TI-RADS 5 nodules had a median of $31.1 \mathrm{kPa},{ }^{16}$ while in the present work, a median of 32.5 $\mathrm{kPa}$ was determined. No previous studies were found that correlated the ACR-TI-RADS classification and SWE with the same cutoff points for analysis of these variables. In another study with similar characteristics, a cutoff point of $34.5 \mathrm{kPa}$ was found to have a sensitivity of $76 \%$ and specificity of $71.1 \%$ in the diagnosis of thyroid cancer, and a cutoff value of $22.30 \mathrm{kPa}$ (with a sensitivity of $82 \%$ and specificity of $88 \%$ ) was shown to allow differentiating malignant from benign lesions. ${ }^{17}$

One of the limitations of our study is that it was not possible to give follow-up to patients with a Bethesda IV-VI result who underwent surgery and, therefore, final result of histopathological complete analysis of the specimen obtained from hemithyroidectomy or total thyroidectomy was not available. One of the strengths of the study is the number of nodules evaluated in a single referral center, which reduces variability in ultrasonographic and histopathological evaluation.

Nodules that had a Bethesda I biopsy result were excluded from statistical analysis; they accounted for $21.2 \%$ of total biopsied nodules, in contrast with 5 to $10 \%$ reported in other studies. ${ }^{6}$ Decreasing the number of non-diagnostic biopsies would be possible if a preliminary cytological result was available before patient discharge, which would allow their correct classification.

In light of the results of this work, we propose to subsequently analyze predictive factors of malignancy in this population, with the comparison of the performance of TI-RADS alone, of SWE alone and with the combination of both tests, since other studies have shown that combined use can have a specificity of up to $95.8 \%$ and sensitivity of $76.29 \%$ in comparison with TI-RADS alone, which has a specificity of 88.24 $\%$ and sensitivity of $89.6 \%$, or with SWE, the specificity of which is $83.1 \%$ and sensitivity, $81.4 \% .^{15}$

An intervention that should be considered is elastography inclusion in ACR TI-RADS criteria, and in those of other associations such as ATA and KTA/ $\mathrm{KSThR},{ }^{18}$ since, although the work was carried out using ACR TI-RADS classification, the use of elastography per se showed an association with cytopathology results.

\section{Conclusions}

SWE is a useful tool in the classification of thyroid nodules: we observed that the greater their stiffness, the higher the possibility of a malignant histopathological result, a relationship that could allow the identification of patients who will require surgical approach. TI-RADS 1-4 nodules with SWE stiffness values lower 
than $21.6 \mathrm{kPa}$ were more likely to be benign, while TI-RADS 5 nodules with stiffness $>32.5 \mathrm{kPa}$ showed a higher risk for being malignant.

\section{Acknowledgements}

We thank the Coordination of Health Research of the Mexican Institute of Social Security for holding the Scientific Article Writing Workshop (TRAC), during which this manuscript was developed.

\section{Conflicts of interest}

The authors declare that they have no conflicts of interest.

\section{Funding}

The authors did not receive any sponsoring to carry out this article.

\section{Ethical disclosures}

Protection of human and animal subjects. The authors declare that the procedures that were followed adhered to the ethical standards of the responsible committee for experimentation on human beings and were in agreement with the World Medical Association and the Declaration of Helsinki.

Confidentiality of data. The authors declare that they followed the protocols of their work center on the publication of patient data.

Right to privacy and informed consent. The authors obtained informed consent from the patients or subjects referred to in the article. This document is in the possession of the corresponding author.

\section{References}

1. American Thyroid Association [website]. Available at thyroid.org.

2. World Health Organization. Mexico. Source: Globocan 2020. [Internet]; 2019. Available at: http://gco.iarc.fr/today/data/factsheets/populations/484-mexico-fact-sheets.pdf

3. Wei X, Li Y, Zhang S, Gao M. Thyroid imaging reporting and data system (TI-RADS) in the diagnostic value of thyroid nodules: a systematic review. Tumour Biol. 2014;35:6769-6776.

4. Ha SM, Baek JH, Na DG, Suh CH, Chung SR, Choi YJ, et al. Diagnostic performance of practice guidelines for thyroid nodules: thyroid nodule size versus biopsy rates. Radiology. 2019;291:92-99.

5. Tessler FN, Middleton WD, Grant EG, Hoang JK, Berland LL, Teefey SA, et al. ACR Thyroid Imaging, Reporting and Data System (TI-RADS): White Paper of the ACR TI-RADS Committee. J Am Coll Radiol. 2017;14:587-595.

6. Cibas ES, Ali SZ. The 2017 Bethesda system for reporting thyroid cytopathology. Thyroid. 2017;27:1341-1346.

7. Hambleton C, Kandil E. Appropriate and accurate diagnosis of thyroid nodules: a review of thyroid fine-needle aspiration. Int J Clin Exp Med. 2013;6:413-422.

8. Kizilkaya MC, Erozgen F, Akinci M, Kaplan R, Tuzun S, Citlak G. The predictive value of elastography in thyroid nodules and its comparison with fine-needle aspiration biopsy results. Ulus Cerrahi Derg. 2014:30:147-152.

9. McQueen AS, Bhatia KS. Thyroid nodule ultrasound: technical advances and future horizons. Insights Imaging. 2015;6:173-188.

10. Zhao CK, Xu HX: Ultrasound elastography of the thyroid: principles and current status. Ultrasonography. 2019;38:106-124.

11. Bhatia KS, Rasalkar DP, Lee YP, Wong KT, King AD, Yuen HY, et al. Cystic change in thyroid nodules: a confounding factor for real-time qualitative thyroid ultrasound elastography. Clin Radiol. 2011;66:799-807.

12. Veyrieres JB, Albarel F, Lombard JV, Berbis J, Sebag F, Oliver C, et al. A threshold value in shear wave elastography to rule out malignant thyroid nodules: a reality? Eur J Radiol. 2012;81:3965-3972.

13. Akobeng AK. Understanding diagnostic tests 3 : Receiver operating characteristic curves. Acta Paediatr. 2007;96:644-647.

14. Hoang JK, Middleton WD, Farjat AE, Langer JE, Reading CC, Teefey SA, et al. Reduction in thyroid nodule biopsies and improved accuracy with American College of Radiology thyroid imaging reporting and data system. Radiology. 2018;287:185-193.

15. Cantisani V, David E, Grazhdani H, Rubini A, Radzina M, Dietrich CF et al. Prospective evaluation of semiquantitative strain ratio and quantitative 2D ultrasound shear wave elastography (SWE) in association with TIRADS classification for thyroid nodule characterization. Ultraschall Med. 2019;40:495-503.

16. Hang J, Li F, Qiao XH, Ye XH, Li A, Du LF. Combination of maximum shear wave elasticity modulus and TIRADS improves the diagnostic specificity in characterizing thyroid nodules: a retrospective study. Int $J$ Endocrinol. 2018;2018:4923050.

17. Liu Z, Jing H, Han X, Shao H, Sun YX, Wang QC, et al. Shear wave elastography combined with the thyroid imaging reporting and data system for malignancy risk stratification in thyroid nodules. Oncotarget. 2017;8:43406-43416.

18. Middleton WD, Teefey SA, Reading CC, Langer JE, Beland MD, Szabunio MM, et al. Comparison of performance characteristics of American College of Radiology TI-RADS, Korean Society of Thyroid Radiology TIRADS, and American Thyroid Association Guidelines. AJR Am J Roentgenol. 2018;210:1148-1154. 